\title{
Grandmothers and Granddaughters: Old-Age Pensions and Intrahousehold Allocation in South Africa
}

\author{
Esther Duflo
}

\begin{abstract}
This article evaluates the impact of a large cash transfer program in South Africa on children's nutritional status and investigates whether the gender of the recipient affects that impact. In the early 1990s the benefits and coverage of the South African social pension program were expanded for the black population. In 1993 the benefits were about twice the median per capita income in rural areas. More than a quarter of black South African children under age five live with a pension recipient. Estimates suggest that pensions received by women had a large impact on the anthropometric status (weight for height and height for age) of girls but little effect on that of boys. No similar effect is found for pensions received by men. This suggests that the efficiency of public transfer programs may depend on the gender of the recipient.
\end{abstract}

Cash transfers are still rare in developing economies. But they are being proposed more often by policymakers and academics as a viable way to redistribute resources. Proponents argue that improvements in the ability to handle cash transfers have made such transactions much easier to implement on a large scale-and less prone to corruption-than in-kind benefits (such as free health or education services). Others worry that redistributing money to adults may be less efficient than subsidizing investment in children if parents do not fully internalize the returns to investing in child health.

There is evidence that inadequate nutrition in childhood affects long-term physical development as well as the development of cognitive skills (Barker 1990). ${ }^{1}$ This in turn affects productivity later in life (Dasgupta 1993; Strauss and Thomas 1998; Schultz 1999). Low levels of investment in child health therefore have far-reaching consequences for economic growth, distribution, and welfare.

Esther Duflo is Professor of Economics at the Massachusetts Institute of Technology. Her e-mail address is eduflo@mit.edu. The author gratefully acknowledges financial suppport from Fondation Thiers and the Alfred P. Sloan Foundation. The author thanks Josh Angrist, Abhijit Banerjee, Tim Besley, François Bourguignon, Anne Case, Pierre-André Chiappori, Angus Deaton, Andrew Foster, Robert Jensen, Michael Kremer, Emmanuel Saez, Duncan Thomas, and three referees for useful comments.

1. Balazs and others (1986) review the biomedical and empirical literature on the relationship between early childhood nutrition and the development of intelligence. Miguel and Kremer (2001) show that school attendance is higher among children treated for worms.

DOI: 10.1093/wber/lhg013

(C) 2003 The International Bank for Reconstruction and Development / THE WORLD BANK 
But cash transfers may result in improvements in the consumption of adults but not in children's human capital, even if investments in child health are inefficiently low.

This debate is closely linked to questions about the optimal design of cash transfers. First, should they be made conditional or unconditional? Evidence from the United States suggests that in-kind transfers (which are a particular kind of conditional transfer)-such as the nutrition supplements distributed under the Special Supplemental Nutrition Program for Women, Infants, and Children (commonly known as the WIC Program)—are associated with greater improvements in children's health than are cash transfers-such as Aid to Families with Dependent Children (Mayer 1997; Currie 1995). Second, do the characteristics of the beneficiaries within the household matter? A growing literature suggests that income or assets in the hands of women are associated with larger improvements in child health and larger shares of household spending on nutrients, health, and housing than are resources in the hands of men (Thomas 1990,1994). Based on this and similar evidence, policymakers have favored transfers targeted to women. A prime example of a program combining these two features is Progresa, a program implemented in Mexico and replicated in several other Latin American countries. Payments are made to women conditional on their children attending school and on their participation in a health care monitoring and food supplementation program. The program has been shown to have significant effects on children's health, nutrition, and education (Gertler and Boyce 2001; Schultz 2000).

Still, there is little evidence that the gender of the recipient affects the impact of a cash transfer program. ${ }^{2}$ The evidence that income in the hands of women is associated with different expenditures than income in the hands of men is suggestive but could be misleading. Families in which women work or own more assets could differ in many respects from families in which women have no access to resources and thus make different decisions. Though the evidence on Progresa suggests that conditional transfers to women can work, it does not answer two other questions: whether unconditional cash transfers can have positive effects and whether these effects are sensitive to the gender of the recipient (because all the recipients were women).

In this article I seek to answer these two questions. I evaluate the impact of the South African old-age pension program (one of the few successful cash transfer programs in the developing world) and compare its effects by gender of the pension recipient using data from a 1993 national household survey. Historically the program was racially discriminatory. At the end of the apartheid era, the

2. The study by Lundberg and others (1996) is an exception. The authors investigate the effects of a change in the mode of allocation of child benefits in the United Kingdom from a tax credit to a direct payment to the mother. This transfer "from the wallet to the purse" appears to have been associated with an increase in the consumption of women's and children's clothing relative to men's clothing in households with children. 
government made a commitment to achieving parity in benefits and eligibility requirements for whites and Africans. ${ }^{3}$ Parity was achieved mostly by increasing the benefits received by Africans. The new system is universal and noncontributory. All women over the age of 60 and all men over age 65 are entitled to benefits, subject to a means test. More than one member of a household can receive the pension at the same time.

In 1993, 80 percent of African women over age 60 and 77 percent of African men over age 65 received the pension. Most received the maximum of 370 rand (R) a month, roughly twice the median per capita income in rural areas. More than a quarter of African children under the age of five live with a pension recipient, because grandparents often live in extended households with their children and grandchildren. ${ }^{4}$ The old-age pension program thus provides an opportunity to evaluate the effect on child nutritional status of an unusually large income transfer that was not targeted specifically to either men or women but could be received by both.

I investigate the effect of men's and women's pensions on child nutrition as reflected in anthropometric indicators-weight for height and height for age. The identification of this effect is complicated by the fact that children living with a pension recipient are relatively disadvantaged on average. Case and Deaton (1998) have shown that the program was effective in transferring money predominantly to poor households, especially to households with poor children. South Africa began to expand the pension program at the end of 1991, and in 1993 the program had been fully operating in all areas for less than a year. Not surprisingly then, because child height in 1993 reflected past as well as current nutrition, children living with a pension recipient were on average smaller for their age than were other children.

To address this problem, I first make use of the fact that pension receipt exhibits a discontinuity at age 60 for women and age 65 for men. Unlike height for age, children's weight for height responds quickly to changes in the environment. I compare the weight for height of children in households with no member eligible for the pension, those in households with an eligible man, and those in households with an eligible woman after controlling for the presence of a man or a woman who is old but not old enough to be eligible (for example, a woman between 55 and 60). The difference is then normalized by the difference in the probability to receive the pension across these two groups. The results suggest that the pensions received by women increased the weight for height of girls by 1.19 standard deviations but did not significantly increase that of boys. Pensions received by men are not associated with an improvement in the nutritional status of either girls or boys.

3. I generally use the official terms for racial groups in South Africa (Africans, whites, colored, and Indians).

4. These living arrangements are due in large part to apartheid rules, which prohibited the families of migrant workers-those working in the mines or as domestic servants-from joining them. 
This comparison would be misleading if there were intrinsic differences between households with a member between age 55 and 60 and households with a member over age 60 or if the expansion of the pension program had led to endogenous changes in the composition of households. Thus, in a second step I make use of the fact that height for age reflects past as well as current nutrition and illnesses. Because all children were measured around the same date, if the pension indeed affects nutrition, older children would have had longer periods of inadequate nutrition. Thus, older children in eligible households should be smaller than those in noneligible households. But for younger children the difference between those in eligible households and those in noneligible households should be reduced or even reversed. The basic idea of the identification strategy is thus to estimate whether the relative disadvantage in height between children in eligible and those in noneligible households are smaller for younger children than for older children. ${ }^{5}$ The results obtained using this second strategy are strikingly similar to those for weight for height: pensions received by women are associated with an increase of 1.16 standard deviations in the height for age of girls but had no significant effect on that of boys. Pensions received by men are not associated with an improvement in the height for age of either boys or girls.

\section{The South African Old-Age Pension Program}

This section presents a brief history and overview of the South African old-age pension program, drawing extensively on Van der Berg (1994), Lund (1993), and Case and Deaton (1998), as well as descriptive statistics on the program.

\section{Description of the Program}

South Africa first introduced social pensions in the 1920s for whites, mainly as a social safety net for the minority of white workers not covered by occupational pensions. The pensions were gradually extended, but with very dissimilar benefit levels, to other racial groups. During the apartheid era the system was racially discriminatory in several respects. First, different means tests were applied to each racial group. In 1984, for example, benefits were withdrawn for incomes larger than R700 a year for Africans but for incomes larger than R2250 a year for whites. Second, the benefit levels were different. In the early 1980s benefits for whites were 10 times those for Africans. ${ }^{6}$ Third, the delivery systems were different. Pensions for whites were distributed through postal offices, whereas those for Africans were distributed through mobile pay points that did not reach very far into rural areas. Finally, officials often intentionally underestimated people's ages, removed people from the computer lists, or otherwise limited the access of legally eligible Africans to reduce the cost of pensions (Lund 1993).

5. In an earlier work I proposed a nonparametric version of this test (Duflo 2000a).

6. The nonpension incomes of Africans were also much smaller, so as a share of income the difference was much smaller (Van der Berg 1994). 
Pressures for equity in the treatment of racial groups became strong toward the end of apartheid, and in 1989 the government made a commitment to achieving racial parity in the pension program (Van der Berg 1994). Extending the social pension to the entire population took several years, and the program was fully operating in all areas only at the beginning of 1993. The benefits for Africans rose gradually in the 1980s-from R1555 a year in 1980 to R2096 in 1990 (both in 1990 rands) - whereas those for whites declined rapidly. The benefits for Africans increased much faster in the 1990s-to R2444 in 1991, to R2677 in 1992, and to R3081 in 1993 (all in 1990 rands). Monthly benefits in 1993 were R370 (1993 rands), and the monthly per capita household income of Africans in the sample averaged R149. Because of the high unemployment in South Africa, pension recipients are often the main income earner in their household.

In 1992 the means test was modified and unified across races. The current system is universal and noncontributory. Payments are made to women over age 60 and to men over age 65 , subject to a means test. In calculating the means test, a couple's resources are roughly divided by two and the income of other household members is not taken into account. The pension program therefore provides no direct incentives to partition the household or for other household members to stop working. In practice, the means test does not seem to be applied very finely. It is mainly effective in excluding most whites as well as Africans with a private pension.

In 1993, 60 percent of men and 77 percent of women in the sample who were eligible on the basis of their age were receiving a pension (table 1). Of these, most received the maximum amount. There is no good estimate of the coverage in earlier periods for two reasons. First, social pensions were administered by several different agencies, which made any evaluation difficult. Second, surveys (including the 1991 census) excluded the independent homelands, where many Africans live. The coverage increased substantially in the 1990s as a result of a new attitude in the program administration, a modification of the means test, computerization of the system, and substantial improvements in the delivery system. ${ }^{7}$

\section{Data and Descriptive Statistics}

The data come from a national survey carried out jointly by the World Bank and the South African Labor and Development Research Unit at the University of Cape Town. During the last five months of 1993, 9000 randomly selected households of all races and in all areas were interviewed. As part of the survey the height and weight of all children under seven years old were measured. Because environmental factors are especially important determinants of height in early childhood, the World Health Organization (wHO) recommends limiting

7. For example, in the province of KwaZulu Natal the pension is distributed once or twice a month through mobile pay points equipped with automated teller machines that have a fingerprint recognition system (Case and Deaton 1998). 
Table 1. Probability of Receiving the Old-Age Pension by Age and Gender and Share of Children in the Survey Living in Households with Adults in this Age and Gender Group, 1993 (percent)

\begin{tabular}{lcc}
\hline & $\begin{array}{c}\text { Share of age group } \\
\text { receiving pension }\end{array}$ & $\begin{array}{c}\text { Share of children living } \\
\text { with age group members }\end{array}$ \\
\hline Men by age (years) & 2.8 & 9.8 \\
$50-54$ & 4.7 & 7.6 \\
$55-59$ & 22.0 & 5.5 \\
$60-64$ & 60.0 & 8.0 \\
65 and over & & \\
Women by age (years) & 13.6 & 8.2 \\
$50-54$ & 16.4 & 10.9 \\
$55-59$ & 77.0 & 21.0 \\
60 and over & & \\
\hline
\end{tabular}

Source: Author's calculation from the 1993 SALDRU national household survey.

the analysis of height and weight measures to children ages zero to five years (wHO 1986). Moreover, there appears to have been problems in the survey with the measurement of the oldest children. ${ }^{8}$ For these reasons I follow earlier studies and restrict the sample to children ages 6-60 months (Case and Deaton 1998; Le Roux 1995). For each age in months I construct height-for-age $z$-scores by subtracting the median and dividing by the standard error in the corresponding age and sex group in the reference population established by the U.S. National Center for Health Statistics (a group of well-nourished U.S. children). I construct weight-for-height $z$-scores in a similar way. ${ }^{9}$

Households with either a woman or a man eligible for the pension have similar characteristics (table 2). But compared with households with no eligible member, these households are poorer even after pension income is included. Not surprisingly, they are often characterized by the presence of a grandparent and the absence of the child's father (67 percent) or mother (18 percent). They are also more likely to live in a rural area.

Children in households with an eligible member are smaller than other children. This is not surprising. Even if the greater coverage and benefits of the pension program had led to better child nutrition, height for age still reflects past deprivations or illnesses, especially among older children. In contrast, average weight for height, a measure of short-run nutritional status, is higher in households with an eligible woman than in those with an eligible man or with no one who is eligible.

8. Some six- and seven-year-old children were recorded as eight by the interviewers and thus not measured. It seems likely that if a child was tall the interviewer would have assumed that the child was older and therefore mistakenly excluded that child.

9. This normalization does not affect the analysis, which relies on the comparison of the height of children in eligible households with that of children of the same age in noneligible households and controls for the child's age. 
Table 2. Descriptive Statistics

\begin{tabular}{|c|c|c|c|}
\hline & \multicolumn{3}{|c|}{ Eligibility for pension } \\
\hline & Woman & Man & None \\
\hline \multicolumn{4}{|l|}{ Housebold characteristics } \\
\hline \multirow[t]{2}{*}{ Mother's education } & 5.70 & 5.78 & 5.17 \\
\hline & $(0.16)$ & $(0.24)$ & $(0.086)$ \\
\hline \multirow[t]{2}{*}{ Father's education } & 5.07 & 4.20 & 4.54 \\
\hline & $(0.27)$ & $(0.46)$ & $(0.11)$ \\
\hline \multirow[t]{2}{*}{ Rural residence } & 0.75 & 0.83 & 0.67 \\
\hline & $(0.018)$ & $(0.028)$ & $(0.012)$ \\
\hline \multirow[t]{2}{*}{ Grandparent in household } & 0.95 & 0.89 & 0.42 \\
\hline & $(0.0081)$ & $(0.021)$ & $(0.012)$ \\
\hline \multirow[t]{2}{*}{ Father is absent } & 0.67 & 0.66 & 0.41 \\
\hline & $(0.020)$ & $(0.033)$ & $(0.012)$ \\
\hline \multirow[t]{2}{*}{ Mother is absent } & 0.18 & 0.14 & 0.08 \\
\hline & $(0.016)$ & $(0.023)$ & $(0.0059)$ \\
\hline \multirow[t]{2}{*}{ Household size } & 10.5 & 10.5 & 7.6 \\
\hline & $(0.21)$ & $(0.30)$ & $(0.086)$ \\
\hline \multicolumn{4}{|l|}{ Income and pension receipt } \\
\hline \multirow[t]{2}{*}{ Man receives pension } & 0.17 & 0.68 & 0.03 \\
\hline & $(0.016)$ & $(0.034)$ & $(0.0041)$ \\
\hline \multirow[t]{2}{*}{ Woman receives pension } & 0.79 & 0.47 & 0.04 \\
\hline & $(0.018)$ & $(0.037)$ & $(0.0050)$ \\
\hline \multirow[t]{2}{*}{ Nonpension income } & 723 & 637 & 908 \\
\hline & (36) & $(51)$ & (22) \\
\hline \multirow[t]{2}{*}{ Pension income } & 325 & 389 & 23 \\
\hline & $(9.6)$ & $(20)$ & $(2.2)$ \\
\hline \multirow[t]{2}{*}{ Per capita income } & 121 & 123 & 149 \\
\hline & $(4.5)$ & $(7.3)$ & (3.9) \\
\hline \multicolumn{4}{|l|}{ Anthropometric data } \\
\hline \multirow[t]{2}{*}{ Height-for-age $z$-score } & -1.38 & -1.46 & -1.21 \\
\hline & $(0.072)$ & $(0.13)$ & $(0.036)$ \\
\hline \multirow[t]{2}{*}{ Weight-for-height $z$-score } & 0.28 & 0.12 & 0.15 \\
\hline & $(0.08)$ & $(0.15)$ & $(0.04)$ \\
\hline Observations & 816 & 286 & 2,380 \\
\hline
\end{tabular}

Note: Standard errors are in parentheses.

Source: Author's calculations.

This suggests that pensions received by women may have led to an improvement in children's health, whereas pensions received by men had no comparable effect. The next two sections elaborate on this evidence.

\section{Effect of the Pension on Weight for Height}

This section presents estimates of the effect of the pension on weight for height, a measure of short-run nutrition and illness. 


\section{Empirical Specification}

The weight for height of children reflects short-run nutrition and illnesses and recovers quickly after periods of malnutrition when proper nutrition is resumed (Ashworth 1969; Martorell and Habicht 1986). Thus, it reflects the impact of current nutrition decisions by parents as well as that of the environment.

Comparing the 1993 weight for height of children living with an eligible woman, an eligible man, or no eligible household member would confound the effect of pension eligibility with the effect of differences in background. To control for these differences, I estimate the effect of having an eligible man or an eligible woman in the household after controlling for the presence of a man or a woman over age 50, a man or a woman over age 55, and a man over age 60 (in 1992) as well as a series of household-specific control variables described later. ${ }^{10}$

Some people who are not yet age-eligible receive the pension, but the probability of receiving the pension does increase discretely at age 60 for women and age 65 for men (see table 1). At the time of the survey the pension program was widely known, so those who were close in age to being eligible for the pension expected to receive it. With the presence of someone close to being eligible controlled for, a positive coefficient of the eligibility dummy variable must therefore indicate the presence of credit constraints. Moreover, even if there are credit constraints, the weight given to the preferences of a woman over age 55 may reflect the fact that she will earn a pension when she turns 60 . To the extent that this is true, the difference between the coefficient of a man's eligibility and that of a woman's eligibility in this specification is an underestimate of the difference between the effect of money given to men and that of money given to women.

The regression estimated is therefore:

$$
w_{i j k}=\pi_{f} E_{f}+\pi_{m} E_{m}+\sum_{j=1}^{4} \gamma_{l} \mathbf{1}_{(l=k)}+W_{i j k} \lambda+X_{i j k} \delta+\omega_{i j k}
$$

where $w_{i j k}$ is the weight-for-height $z$-score of a child born in cohort $k$ in family $f, E_{f}$ is equal to one if there is an eligible woman in the household and zero otherwise, $E_{m}$ is equal to one if there is an eligible man in the household and zero otherwise, and $\mathbf{1}_{(l=k)}$ is a dummy variable indicating the year of birth of the child. $W_{i j k}$ is a vector of variables indicating whether there is a woman over age 51 in the household, a man over age 50, a woman over age 56, a man over age 56, and a man over age $61 .{ }^{11} X_{i j k}$ is a vector of family background variables: mother's and father's education levels; rural, urban, or metropolitan residence; mother's and father's ages; size of household; and the number of household members in the age categories $0-5,6-14,15-24$, and $25-49$ years. ${ }^{12}$

10. This strategy was used by Case and Deaton (1998), Bertrand and others (1999), and Edmonds and others (2001).

11. Thus, these individuals were respectively age 49, 55, and 60 in 1992.

12. I have replaced the relevant variables with sample means where the father or mother of the child was absent. 
Table 3. Effect of the Old-Age Pension Program on Weight for Height: ols and 2sLs Regressions

\begin{tabular}{|c|c|c|c|c|c|c|c|}
\hline \multirow[b]{2}{*}{ Variable } & \multicolumn{6}{|c|}{ OLS } & \multirow{2}{*}{$\frac{2 \mathrm{SLS}}{(7)}$} \\
\hline & $(1)$ & $(2)$ & (3) & (4) & $(5)$ & (6) & \\
\hline \multicolumn{8}{|l|}{ Girls } \\
\hline Eligible household & $\begin{array}{r}0.14 \\
(0.12)\end{array}$ & $\begin{array}{l}0.35^{*} \\
(0.17)\end{array}$ & $\begin{array}{c}0.34 * \\
(0.17)\end{array}$ & & & & \\
\hline Woman eligible ${ }^{a}$ & & & & $\begin{array}{l}0.24 * \\
(0.12)\end{array}$ & $\begin{array}{c}0.61 * \\
(0.19)\end{array}$ & $\begin{array}{l}0.61 * \\
(0.19)\end{array}$ & $\begin{array}{l}1.19^{*} \\
(0.41)\end{array}$ \\
\hline Man eligible ${ }^{b}$ & & & & $\begin{array}{r}-0.011 \\
(0.22)\end{array}$ & $\begin{array}{r}0.11 \\
(0.28)\end{array}$ & $\begin{array}{l}0.056 \\
(0.19)\end{array}$ & $\begin{array}{r}-0.097 \\
(0.74)\end{array}$ \\
\hline Observations & 1574 & 1574 & 1533 & 1574 & 1574 & 1533 & 1533 \\
\hline \multicolumn{8}{|l|}{ Boys } \\
\hline Eligible household & $\begin{array}{r}0.0012 \\
(0.13)\end{array}$ & $\begin{array}{l}0.022 \\
(0.22)\end{array}$ & $\begin{array}{l}0.030 \\
(0.24)\end{array}$ & & & & \\
\hline Woman eligible ${ }^{a}$ & & & & $\begin{array}{r}0.066 \\
(0.14)\end{array}$ & $\begin{array}{r}0.28 \\
(0.28)\end{array}$ & $\begin{array}{r}0.31 \\
(0.28)\end{array}$ & $\begin{array}{r}0.58 \\
(0.53)\end{array}$ \\
\hline Man eligible ${ }^{b}$ & & & & $\begin{array}{r}-0.059 \\
(0.22)\end{array}$ & $\begin{array}{l}-0.25 \\
(0.34)\end{array}$ & $\begin{array}{l}-0.25 \\
(0.35)\end{array}$ & $\begin{array}{l}-0.69 \\
(0.91)\end{array}$ \\
\hline Observations & 1670 & 1670 & 1627 & 1670 & 1670 & 1627 & 1627 \\
\hline $\begin{array}{l}\text { Control variables } \\
\text { Presence of older membersc }\end{array}$ & No & Yes & Yes & No & Yes & Yes & Yes \\
\hline Family background variables ${ }^{\mathrm{d}}$ & No & No & Yes & No & No & Yes & Yes \\
\hline Child age dummy variables ${ }^{\mathrm{e}}$ & Yes & Yes & Yes & Yes & Yes & Yes & Yes \\
\hline
\end{tabular}

"Significant at the 5 percent level.

Note: The instruments in column 7 are woman eligible and man eligible (the first stage is in table A-1). Standard errors (robust to correlation of residuals within households and heteroscedasticity) are in parentheses.

an column 7 this variable is replaced by a dummy for whether a woman receives the pension.

bIn column 7 this variable is replaced by a dummy for whether a man receives the pension.

cPresence of a woman over age 50 , a man over age 50 , a woman over age 56 , a man over age 56 , and a man over age 61 .

'Father's age and education; mother's age and education; rural or metropolitan residence (urban is the omitted category); size of household; and number of members ages $0-5,6-14,15-24$, and 25-49.

eDummy variables for whether the child was born in 1991, 1990, or 1989.

Source: Author's calculations.

The identification assumption underlying this exercise is that there is no systematic difference in nutrition between eligible and noneligible households with an elderly member. As I discuss later, this assumption may be problematic, and I present results for an alternative specification that relaxes it.

\section{Results}

The results from estimating equation 1 are presented in table 3. Columns 1-3 do not distinguish by gender of the eligible household member. For girls the coefficient is positive but insignificant without controlling for the presence of noneligible members over age 50 (column 1 ). When these controls are introduced, the coefficient more than doubles (0.35) and becomes significant (column 2). 
Introducing additional control variables does not affect the coefficient (column 3 ). As expected, because extended families tend to be poorer than nuclear families, the direct effect of having household members over age 56 (not reported here) is negative and similar across genders. The similarity between the coefficients in columns 2 and 3 is reassuring. It suggests that the dummy variables for the presence of elderly members capture the effect of observed (and hopefully unobserved) family variables. For boys there seems to be no effect from having an eligible household member, regardless of whether the presence of other elderly members in the household is controlled for.

Columns 4-6 estimate the effects separately according to the gender of the eligible household member. For girls column 6 suggests that having a woman eligible increases weight for height by 0.6 standard deviation (with a standard error of 0.19). In contrast, having a man eligible increases weight for height by an insignificant 0.056 standard deviation. The coefficients on men's and women's eligibility differ statistically from each other. (The $F$-statistic is 2.50 , with a $p$-value of 0.11.) For boys we can now detect a smaller (0.28 standard deviation) and insignificant positive effect of a woman's eligibility on weight for height and a negative (and insignificant) effect of a man's eligibility. Again, the coefficients are very similar in columns 5 and 6.

Column 7 checks that the difference between the coefficient of a man's pension income and that of a woman's pension income is not simply due to the fact that, conditional on being age-eligible, men claim the pension much less often than women (perhaps because they are more likely to have worked and to have a private pension). To do this, I estimate the following relationship using twostage least squares (2sLS):

$$
w_{i h k}=a_{f} P E N S_{f}+a_{m} P E N S_{m}+\sum_{j=1}^{4} \gamma_{j} 1_{(j=k)}+W_{i h k} \lambda+X_{i h k} \delta+w_{i h k}
$$

where $P E N S_{f}$ is a dummy variable indicating whether a woman in the household receives a pension and $P E N S_{m}$ a dummy variable indicating whether a man in the household receives a pension. The instruments are dummy variables for the presence of an eligible woman and the presence of an eligible man. Not surprisingly, the first stage is strong (table A-1, columns 1 and 2). The coefficient of the eligible man dummy variable in the regression predicting a male pension is 0.39 (with a $t$-statistic of 8 ), and that of the eligible woman dummy variable in the regression predicting a female pension is 0.55 (with a $t$-statistic of more than 9). ${ }^{13}$

The results in column 7 of table 3 confirm that the differences between the effects of men's and women's pension eligibility found in columns 5 and 6 are not an artifact of the smaller first stage for a man's pension. For girls these estimates suggest that a woman's pension increases weight for height by 1.19 standard deviations, whereas a man's pension has a small, negative, insignificant

13. These coefficients reflect the difference between the probability of receiving the pension when eligible and that of receiving the pension when close to eligibility. 
Table 4. Effect of Pension Eligibility on Weight for Height by Gender of the Intermediate Generation: OLS Regressions

\begin{tabular}{lcc}
\hline Variable & Girls & Boys \\
\hline Mother's mother eligible & $0.48^{*}$ & 0.099 \\
& $(0.21)$ & $(0.27)$ \\
Father's mother eligible & 0.15 & 0.29 \\
& $(0.25)$ & $(0.30)$ \\
Mother's father eligible & 0.097 & 0.00052 \\
& $(0.34)$ & $(0.43)$ \\
Father's father eligible & 0.22 & 0.25 \\
& $(0.48)$ & $(0.44)$ \\
Observations & 1457 & 1552 \\
Control variables & & \\
Presence of older members & Yes & Yes \\
Family background variables & Yes & Yes \\
Age dummy variables & Yes & Yes \\
\hline
\end{tabular}

*Significant at the 5 percent level.

Note: Standard errors (robust to correlation of residuals within households and heteroscedasticity) are in parentheses.

aDummy variables for whether there is a woman over age 50, a man over age 50 , a woman over age 56 , a man over age 56 , and a man over age 61 .

'Father's age and education; mother's age and education; rural or metropolitan residence; size of household; and number of members ages $0-5,6-$ 14, 15-24, and 25-49.

'Dummy variables for whether the child was born in 1991, 1990, or 1989.

Source: Author's calculations.

effect. For boys the coefficient of a woman's pension is positive but only half as large as the effect for girls (0.58) and insignificant (the standard error is 0.53). The coefficient of a man's pension is negative $(-0.69)$ and insignificant.

I also examine whether the gender of the parent whose own parent is eligible has an effect as well. Strikingly, only the eligibility of the mother's mother has a significant effect on girl's weight for height (table 4).

These results provide some suggestive evidence that the old-age pension had very different effects on child health depending on whether it was received by a woman or by a man. Moreover, there appears to be an all-female link, because the pension seems to be effective only if received by the mother of a girl's mother. There are caveats to this interpretation, however, which I now discuss.

\section{Can Unobserved Differences between Eligible and Noneligible Households Explain the Results?}

The essential difficulty is whether controlling for the presence of members over age 50,56, and 61 adequately controls for the differences between eligible and noneligible households. A first problem could be differences between households with a member over age 55 and those with a member over age 60 . For example, conditional on a household's having three generations, the presence of an elderly grandparent may be a sign of a relatively healthy household. That a grandmother 
is old indicates that she, the mother, or both did not have children very early. (It could also indicate that the grandmother had many children, but I control directly for this.) That the grandmother is old but still alive could indicate that household members are generally healthy. Both effects would bias upward the estimate of the effect of the pension on weight for height.

A second problem is the possibility that the pension program led to changes in the composition of the household. Endogenous household composition could create a positive correlation between unobserved household characteristics and the presence of an eligible member. A difference between the coefficient of a woman's pension and that of a man's could then be obtained even in the absence of any causal effect of the additional income on nutrition.

\section{Effect of the Pension on Height for Age}

Some of these problems, which plague any cross-sectional comparison of households by eligibility status, could be addressed by comparing health status in households with eligible members with that in households without eligible members, before and after the expansion of the pension program. There were no representative surveys of African households before the end of apartheid. But we can take advantage of the fact that height is a stock reflecting accumulated investment in a child's health and nutrition since birth.

\section{Empirical Specification}

In developing economies human growth deficits are caused by two preventable factors: inadequate food and infections. Genetic factors matter in child height, but they become more critical in adolescence. The height for age of young children depends on accumulated investments over the life of the child (Martorell and Habicht 1986).

I capture this by writing the height for age of child $i$ at age $a$ as a function of nutrition since birth: $h_{i}(a)=\phi\left(N_{0 i} \ldots, N_{a i}\right)$, where $h_{i}(a)$ is the height-for-age $z$-score attained by child $i$ at age $a$, and $N_{s i}$ (for $s=0$ to $a$ ) is the ratio of the nutrition and other necessary inputs (primary health care and the like) received by the child relative to what would be optimal at each age. The function $\phi($.$) is$ weakly increasing in all its arguments, and $\phi(1,1 \ldots, 1)=0$.

Some properties of the function $\phi($.$) are documented in the medical literature.$ First, nutrition at a very early age (in the womb and in infancy) has long-lasting effects on child height and indeed on adult health (Barker 1990; Scrimshaw 1997). Second, the possibility of catch-up skeletal growth after an episode of low growth in infancy is limited. ${ }^{14}$ Most stunting and catch-up occurs between 6 and 24 months of age. Stunting after 24 months of age generally reflects the interaction of nutrition and infection at earlier ages (Martorell and Habicht 1986).

14. For example, a study in Jamaica shows that children's weight for height recovers quickly from episodes of acute malnutrition, but that once normal weight for height is achieved, the body stops accumulating nutrients that would allow faster skeletal growth (Ashworth 1969). 
Given this, if households eligible for pensions have worse characteristics than noneligible households, older children would be smaller in eligible households. But if the expansion of the pension program led to better nutrition, children measured when they were younger would have been well nourished for a larger fraction of their lives. Therefore, the younger the children are, the smaller their relative disadvantage should be in eligible households. If the pension program led to a substantial improvement in nutrition (as suggested by the previous section), the youngest children in eligible households should even be taller for their age than children of the same age in noneligible households.

The basic idea of the identification strategy is thus to compare the difference in height between children in eligible and those in noneligible households among children exposed to the program for a fraction of their lives to the same difference among children exposed all their lives. Figure 1 illustrates this identification strategy. I run a nonparametric regression of height for age on age in months for children living with an eligible woman, for those living with an eligible man, and for those living with no eligible household members (children living with both an eligible man and an eligible woman are included in both regressions). The curves have the traditional pattern for height for age in developing countries (Martorell and Habicht 1986). Height for age declines steeply in the first two years of life and then stabilizes.

The relative position of the curves is of interest. Older children living with an eligible woman are smaller than those with no eligible member in their household. The relative advantage of noneligible children increased for children born between June and December 1990 (noneligible children in that age group appeared to be taller for their age). Starting in January 1991 (when the pension program began to expand), the difference becomes smaller, and children born by the end of 1991 are taller if they live with an eligible woman. Duflo (2000a) presents more nonparametric evidence of the effect of the program (without distinguishing by the recipient's gender), showing that the difference in its effect for eligible and noneligible girls has a significant positive slope after January 1991. This catch-up is not apparent for young children living with an eligible grandfather, ${ }^{15}$ even though the height for age of the older children living with an eligible grandfather is very similar to that of children living with an eligible grandmother.

This discussion suggests the following formulation for comparing the effect of a woman's pension eligibility on height for age with that of a man's:

$$
\begin{aligned}
h_{i j k}= & \pi_{f}\left(\text { YOUNG } * E_{f}\right)+\pi_{m}\left(\text { YOUNG } * E_{m}\right)+\beta_{f} E_{f}+\beta_{m} E_{m}+\sum_{l=1}^{4} \gamma_{j} 1_{(l=k)} \\
& +X_{i j k} \delta+\sum_{l=1}^{4} 1_{(l=k)} * X_{i j k} \lambda_{j}+\epsilon_{i k k}
\end{aligned}
$$

where $h_{i j k}$ is the height-for-age $z$-score of a child born in cohort $k$ in family $j$, and the notation is otherwise as before. Children born in January 1992 or later, after the full expansion of the pension program, form the most exposed group

15. The catch-up at the extreme right of figure 1 is due to one outlier. 
Figure 1. Height for Age of Children Living with Eligible Women, Eligible Men, No Eligible Member

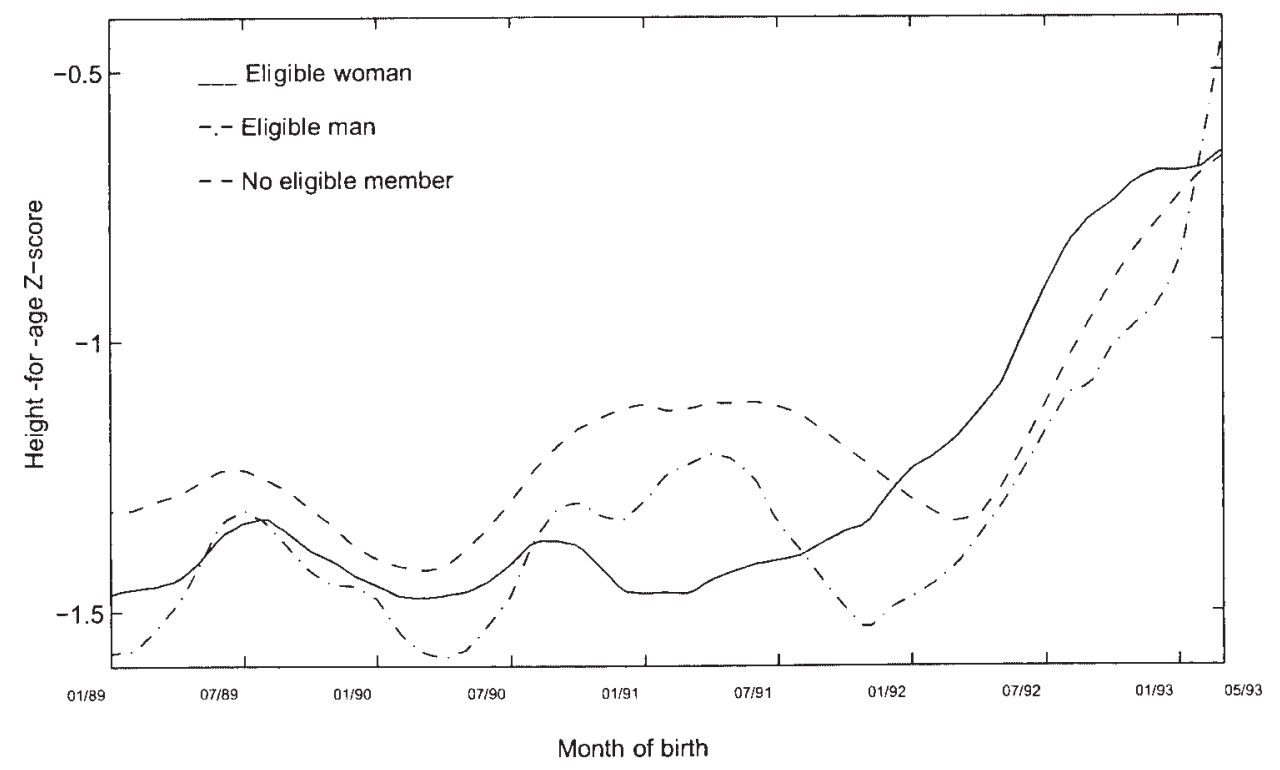

(YOUNG). The last two terms $\left(X_{i j k}\right.$ and $\left.\sum_{j=1}^{4} 1_{(l=k)} * X_{i j k}\right)$ are family background variables (those discussed in the previous section, plus a control variable for the presence of a household member over age 50) and family background variables interacted with cohort dummy variables. Equation 3 is estimated using ordinary least squares (OLS), and standard errors are adjusted to take into account the correlation of error terms between children in the same families as well as heteroscedasticity.

Because even older children were exposed to the program for a fraction of their lives, the difference-in-differences estimate is a downward-biased estimate of the effect of the eligibility (and of the difference between the effects of men's and women's eligibility) unless nutrition at a very early age is the only significant determinant of height by age five.

\section{Results}

The results from estimating equation 3 are presented in table 5. Column 1 estimates the effect of pension eligibility. For girls, living with an eligible household member is associated with an increase of 0.68 standard deviation in height for age. The uninteracted effect of eligibility is negative but substantially smaller than the interaction $(-0.17)$ and insignificant after the control variables are introduced. This result is reassuring, because it reduces the likelihood that eligible and noneligible households are subject to different shocks (such as different programs). 
Table 5. Ols and 2sls Regressions of the Effect of Pension Eligibility, Presence of an Old Grandparent, and Pension Receipt

\begin{tabular}{|c|c|c|c|c|}
\hline & & Treatm & t variable & \\
\hline & $\begin{array}{c}\text { Eligibility } \\
\text { OLS } \\
(1)\end{array}$ & $\begin{array}{c}\text { Eligibility } \\
\text { OLS } \\
(2)\end{array}$ & $\begin{array}{c}\text { Old } \\
\text { grandparent } \\
\text { OLS } \\
\text { (3) }\end{array}$ & $\begin{array}{c}\text { Receives } \\
\text { pension } \\
2 \text { sLS } \\
(4)\end{array}$ \\
\hline Girls & & & & \\
\hline Eligible household $\times$ YOUNG & $\begin{array}{r}0.68 * \\
(0.37)\end{array}$ & & & \\
\hline Woman treatment variable $\times$ YOUNG & & $\begin{array}{l}0.71 * \\
(0.34)\end{array}$ & $\begin{array}{c}0.40 \\
(0.27)\end{array}$ & $\begin{array}{l}1.16^{*} \\
(0.56)\end{array}$ \\
\hline Man treatment variable $\times$ YOUNG & & $\begin{array}{l}0.097 \\
(0.57)\end{array}$ & $\begin{array}{l}-0.12 \\
(0.35)\end{array}$ & $\begin{array}{c}-0.071 \\
(0.95)\end{array}$ \\
\hline Eligible household & $\begin{array}{l}-0.17 \\
(0.16)\end{array}$ & & & \\
\hline Woman pension variable & & $\begin{array}{c}-0.15 \\
(0.17)\end{array}$ & $\begin{array}{c}-0.039 \\
(0.13)\end{array}$ & $\begin{array}{c}-0.15 \\
(0.17)\end{array}$ \\
\hline Man pension variable & & $\begin{array}{l}-0.11 \\
(0.24)\end{array}$ & $\begin{array}{l}0.027 \\
(0.15)\end{array}$ & $\begin{array}{l}-0.11 \\
(0.24)\end{array}$ \\
\hline Observations & 1533 & 1533 & 1533 & 1533 \\
\hline Boys & & & & \\
\hline Eligible household $\times$ YOUNG & $\begin{array}{c}0.11 \\
(0.31)\end{array}$ & & & \\
\hline Woman pension variable $\times$ YOUNG & & $\begin{array}{c}0.18 \\
(0.32)\end{array}$ & $\begin{array}{r}0.026 \\
(0.27)\end{array}$ & $\begin{array}{l}0.28 \\
(0.47)\end{array}$ \\
\hline Man pension variable $\times$ YOUNG & & $\begin{array}{l}-0.30 \\
(0.32)\end{array}$ & $\begin{array}{c}0.18 \\
(0.30)\end{array}$ & $\begin{array}{l}-0.47 \\
(0.71)\end{array}$ \\
\hline Eligible household & $\begin{array}{l}-0.15 \\
(0.15)\end{array}$ & & & \\
\hline Woman pension variable & & $\begin{array}{l}-0.14 \\
(0.32)\end{array}$ & $\begin{array}{c}-0.084 \\
(0.69)\end{array}$ & $\begin{array}{l}-0.15 \\
(0.17)\end{array}$ \\
\hline Man pension variable & & $\begin{array}{c}-0.073 \\
(0.21)\end{array}$ & $\begin{array}{c}-0.011 \\
(0.14)\end{array}$ & $\begin{array}{c}-0.057 \\
(0.21)\end{array}$ \\
\hline Observations & 1627 & 1627 & 1627 & 1627 \\
\hline $\begin{array}{l}\text { Control variables } \\
\text { Age dummy variables }{ }^{\mathrm{a}}\end{array}$ & Yes & Yes & Yes & Yes \\
\hline Family background variables ${ }^{b}$ & Yes & Yes & Yes & Yes \\
\hline $\begin{array}{l}\text { Family background variables } \times \\
\text { age dummy variables }\end{array}$ & Yes & Yes & Yes & Yes \\
\hline
\end{tabular}

*Significant at the 10 percent level.

Note: Standard errors (robust to correlation of residuals within households and heteroscedasticity) are in parentheses.

aDummy variables for whether the child was born in 1991, 1990, or 1989.

bFather's age and education; mother's age and education; rural or metropolitan residence; size of household; and number of members ages $0-5,6-14,15-24,25-49$, and over 50 .

Source: Author's calculations. 
For boys the effect of eligibility is small $(0.11)$ and insignificant. The uninteracted effect of eligibility is similar to that on girls' height $(-0.15)$.

Column 2 estimates the effect distinguishing by gender of the household member eligible for the pension. Having an eligible woman in the household increases the height for age of young girls relative to older ones by 0.71 standard deviation (with a standard error of 0.34). Having an eligible man in the household has a small and negative effect. For boys the coefficient of the interaction between a woman's eligibility and a dummy variable for being young is only 0.18 (and insignificant) and that of the interaction between a man's eligibility and a dummy variable for being young is negative and insignificant.

As in the weight-for-height specification, I estimate the effect of the pension implied by these coefficients using 2 sLs:

$$
\begin{aligned}
h_{i j k}= & a_{f}\left(\text { YOUNG }^{*} \text { PENS }_{f}\right)+a_{m}\left(\text { YOUNG }^{*} * P E N S_{m}\right)+\beta_{f} E_{f}+\beta_{m} E_{m} \\
& +\sum_{j=1}^{4} \gamma_{j} 1_{(j=k)}+X_{i f k} \delta+\sum_{j=1}^{4} 1_{(k=j)} * X_{i f k} \lambda_{j}+\epsilon_{i f k}
\end{aligned}
$$

where $P E N S_{f}$ is a dummy variable equal to one if a woman receives a pension, and $P E N S_{m}$ a dummy variable equal to one if a man receives a pension. The interactions YOUNG $* P E N S_{f}$ and $Y O U N G * P E N S_{m}$ are endogenous, and they are instrumented using the interactions (YOUNG $\left.* E_{f}\right)$ and $\left(Y O U N G * E_{m}\right){ }^{16}$

The results suggest that pensions received by women led to an increase of at least 1.16 standard deviations in the height of girls and to a much smaller (and insignificant) effect ( 0.28 standard deviation) on the height of boys (table 5, column 4). Pensions received by men appear to have had no effect on the height of boys or girls. These results are strikingly similar to those for weight for height.

In table 6 I consider separately the effect of pension eligibility of the mother's mother, the father's mother, the mother's father, and the father's father. Again, the eligibility of the mother's mother had the strongest effect on the nutritional status of girls.

It is reassuring to see that the two outcome measures (weight for height and height for age) and the two strategies lead to the same results. Nevertheless, these results could be tainted by failures of the identification assumption, which I now consider.

\section{Controlling for Endogenous Household Formation and for Other Programs}

The comparison between older and younger children in eligible and noneligible households helps address some of the earlier concerns. In particular, any difference between eligible and noneligible households that affects older and younger

16. An alternative specification would be to control for uninteracted pension receipt, instrumented by the uninteracted eligibility variable. The reduced form would be identical, and the coefficients of the interaction YOUNG * PENS similar. Because the main effect of PENS cannot be interpreted, this is the preferred specification. 
Table 6. Effect of Pension Eligibility on Height for Age by Gender of the Intermediate Generation: ols Regressions

\begin{tabular}{lcc}
\hline & Girls & Boys \\
\hline Mother's mother eligible $\times$ YOUNG & 0.94 & 0.23 \\
& $(0.56)$ & $(0.51)$ \\
Father's mother eligible $\times$ YOUNG & 0.76 & -0.34 \\
& $(0.53)$ & $(0.54)$ \\
Mother's father eligible $\times$ YOUNG & -0.69 & -0.70 \\
& $(0.65)$ & $(0.82)$ \\
Father's father eligible $\times$ YOUNG & 0.33 & 0.36 \\
& $(0.69)$ & $(0.81)$ \\
Observations & 1457 & 1552 \\
Control variables & & \\
Family background variables & & \\
Age dummy variables & & Yes \\
Eligibility variables & Yes & Yes \\
Family background variables $\times$ & Yes & Yes \\
age dummy variables & Yes & Yes \\
\hline
\end{tabular}

Note: Standard errors (robust to correlation of residuals within households and heteroscedasticity) are in parentheses.

aFather's age and education; mother's age and education; rural or metro residence; size of household; and number of members ages $0-5,6-14,15-24,25-49$, and over 50 .

'Dummy variables for whether the child was born in 1991, 1990, or 1989. 'Mother's mother eligible, father's mother eligible, mother's father eligible, and father's father eligible (the first stage is in table A-1).

Source: Author's calculations.

children in a similar way is controlled for. Even so, there could still be age-specific differences in nutritional status across households.

Endogenous Household Formation. As discussed, household composition may have changed as a result of the program, and this could invalidate the proposed identification strategy if parents became more (or less) likely to send their children to live with their grandparents or to have the grandparents live with them. If this did not depend on the age of the child, this would not invalidate the spirit of the strategy. But it is conceivable that the correlation between child health and household composition for young children differs from that for older children.

To address this problem, I use an alternative variable that is correlated with the presence of an eligible member in the household but is not affected by household decisions. This is a dummy variable indicating whether the child has at least one grandparent who is alive and eligible or likely to be eligible. The dummy variable takes the value of one if there is an eligible person in the household or if one of the following is true: the mother (the father) of the child is older than age 34 and her (his) mother is alive, or the mother (father) of the 
child is older than age 32 and her (his) father is alive. ${ }^{17}$ Among children who have a living old grandparent, 46 percent live with a pension recipient. This variable is therefore still strongly correlated with pension receipt. Using the variable as an alternative instrument for pension receipt would be inappropriate, because it will also capture possible changes in transfers by (or to) a noncoresident grandparent. ${ }^{18}$

Estimates of a difference-in-differences specification that is similar to the reduced form equation 3 but uses the indicator for whether the child has a living elderly grandparent rather than eligibility status are presented in table 5 (column 3). For girls, having a living old grandmother has a positive (but significant at only 15 percent) effect, though it is smaller than the estimated effect of a woman's eligibility. This result is expected, because the probability of receiving the pension is higher for those living with an eligible household member than for those with a living elderly grandparent, and interhousehold transfers may not fully compensate for this difference. The effect of having a living elderly grandfather is small and insignificant. For boys, having a living old grandfather or grandmother has no effect.

Using this alternative variable reduces the precision of the results, but it does not change the conclusions. Thus, it confirms that the previous results are not likely to be an artifact of endogenous household formation.

Unobserved Characteristics of Government Programs. Could the results be explained by age-specific differences in nutritional status between children living in households with an eligible woman and children living in other households?

Younger girls are taller in households with an eligible woman relative to girls of the same age in noneligible households. When I estimate the effect of eligibility on weight for height (equation 1) separately for younger and older girls, the coefficients of a woman's pension eligibility are 0.71 and 0.56 . Both numbers differ significantly from zero but not from each other. These results are therefore unlikely to be driven by the fact that all children receive worse nutrition when they live with an eligible grandmother but that the effects are stronger for older children. The similarity of the effects on the weight for height of younger and older children suggests that the results are not due to a program targeting younger children in eligible households.

Similar results would still be obtained if children (older and younger) living with eligible grandmothers were also more likely to be targeted by other nutri-

17. I determined the cutoffs of 32 and 34 years by using the information on extended families in my sample. Women whose observed child is older than 34 and men whose observed child is older than 32 have a 60 percent probability of being eligible for the pension. Results are not sensitive to the choice of cutoff. If a parent is not in the household, the survey does not indicate his or her age or whether his or her parents are alive. So some children may have a living old grandparent not identified in the data.

18. Jensen (1998) shows that intergenerational transfers changed in response to the program: transfers from children to parents were reduced when parents became eligible. 
tion or government health programs. South Africa had two nutritional programs in place in the early 1990s (Budlender 2000). The Protein Energy Malnutrition Scheme, in place since the 1960s, subsidized the purchase of powdered skim milk for distribution to malnourished preschool children. The program was modified and expanded in mid-1993 (its annual budget was increased to R40 million, eight times its former budget, and its target group was broadened). Because the sample excludes children born later than July 1993, it would not be affected by this expansion. The National Development Program (later renamed the National Nutrition and Social Development Program) was introduced in 1990-91 to compensate for the planned introduction of a value-added tax on basic foodstuffs, with an annual budget of R400 million. This food distribution program (not particularly focused on children) was implemented at the local level through nongovernmental and community-based organizations. Because of the program's decentralized implementation, it is impossible to document which households benefited more. But because those eligible for pensions are generally poorer, they are more likely to have been in the target groups.

Three pieces of evidence suggest that these programs do not account for the results. First, the characteristics of households with eligible women and those with eligible men are very similar. Thus, it appears unlikely that a program would have disproportionately targeted children living with their grandmothers rather than all children living in extended families. Of course, grandmothers might be more likely than grandfathers to take advantage of these programs. But the interaction between the child's age and the presence of a woman over age 50 (but not eligible) has the same coefficient as that between the child's age and the presence of man over age 50, providing no support for this alternative explanation. Second, the regressions control for a range of observed household variables interacted with age dummy variables and should therefore capture the effect of any program targeted according to these variables. When these variables are controlled for, older children are not significantly smaller in eligible households, suggesting that they are unlikely to have been targeted by other programs. Third, the point estimates obtained with the alternative instruments (grandmother or grandfather alive and old) are similar to those obtained using eligibility variables as instruments. The characteristics of households in which children have a living grandmother are similar to those in which children do not have one. Thus it is unlikely that they would have been subject to different programs.

\section{INTERPRETATION}

The evidence appears to indicate that pensions received by women had a large effect on child nutrition, whereas pensions received by men did not. But several interpretations of this evidence are possible.

One interpretation is that the same resources are spent differently depending on whether they are received by a woman or by a man. This interpretation would 
have important implications for public policy. In particular, it suggests that if improving children's nutrition is a policy objective, targeting public transfers to women rather than to men might be preferable.

A second interpretation is that, in terms of permanent income, a rand of pension received by a man represents much less than a rand of pension received by a woman because men are expected to receive the pension for a shorter time. This difference could lead to different effects from men's and women's pensions if households have an ability to smooth consumption over time through savings or borrowing.

To help discriminate between these two interpretations, it is useful to look at the disposition of men's and women's pension income. If the household is a unitary entity and if a man's pension income is not spent on child health because it is akin to transitory income, the propensity to save out of a man's pension income should be much larger than the propensity to save out of a woman's pension income (and nonpension income). To examine this possibility, I estimate the following equation:

$$
S_{b}=\alpha_{f} y_{b f}+\alpha_{m} y_{b m}+\alpha z_{b}+X_{b} \beta+\epsilon_{b}
$$

where $S_{b}$ is the total savings of the household (defined as total income minus expenditures), $y_{b f}$ is pension income received by a woman, $y_{b m}$ is pension income received by a man, $z_{b}$ is nonpension income, and $X_{b}$ is a set of control variables. This specification extends the Case and Deaton (1998) formulation to take into account differences in the disposition of income received by men and women. The emphasis here is on the comparison between $\alpha_{f}$ and $\alpha_{m}$. The equation is estimated using both oLs and 2 sLs. The instruments in the 2 sLs equations (for $y_{b f}, y_{b m}$, and $z_{b}$ ) are the indicators for the presence of an eligible man and an eligible woman and the instruments used to correct for measurement errors in nonpension income (see notes to table 7).

The point estimates suggest that the propensity to save out of a man's pension income is lower than the propensity to save out of a woman's pension income, although the difference is not significant (table 7). ${ }^{19}$ This result indicates that the differences in the effects of women's and men's pension income on child height are unlikely to be due to the differences in their life cycles.

The argument could then be reversed. If child nutrition is an investment, grandmothers' expectations of a longer life would lead them to invest more in their grandchildren, because they are more likely to reap the benefits of this investment. This could explain the fact that the elasticity of child nutrition with respect to the grandmother's income is larger than that with respect to the grandfather's. In this case the differences in the effect of pension income on child nutrition have nothing to do with the gender of the recipient per se; instead, the differences result from the fact that, in this particular program, female

19. The very large estimated propensity to save out of nonpension income should not be taken at face value. It reflects mismeasurement of income and consumption, common in this type of survey. 
Table 7. Propensity to Save out of Pension Income and Nonpension Income: OLS and 2sLS Regressions

\begin{tabular}{lcc}
\hline \multirow{2}{*}{ Variable } & \multicolumn{2}{c}{ Savings } \\
\cline { 2 - 3 } & OLS & 2SLS \\
\hline Woman's pension income & $0.99 *$ & $0.82 *$ \\
Man's pension income & $(0.093)$ & $(0.16)$ \\
& $0.78^{*}$ & $0.53 *$ \\
Nonpension income & $(0.13)$ & $(0.22)$ \\
& $0.53 *$ & $0.50 *$ \\
& $(0.017)$ & $(0.041)$
\end{tabular}

*Significant at the 5 percent level.

Note: Standard errors are in parentheses. Instruments are dummy variables for household head is employed; household head holds a regular job, a casual wage job, a job in agriculture; sector of the job; type of employer (central or local government, private firm, other); type of pay (weekly, fortnightly, monthly); woman eligible; and man eligible.

Source: Author's calculations.

recipients are younger and live longer. However, when I reestimate the relationships of child height for age and weight for height in a sample that includes only eligible men living with an eligible woman, the results (not presented here) are unchanged.

Grandmothers are likely to have a stronger incentive than grandfathers to invest in children because they will benefit from them for a longer time. But the fact that this difference in preferences results in a difference in outcomes shows that individual preferences and bargaining power matter for how expenditures are allocated. These results thus provide new evidence that households do not function as a unitary entity (Chiappori 1988, 1992; Browning and Chiappori 1998), evidence untainted by the empirical problems (such as assortative matching and endogeneity of income) affecting earlier studies. ${ }^{20}$ This in turn suggests that the identity of the recipient is an important parameter in the design of a public transfer program, even though it cannot be inferred from these results that grandmothers have a stronger inherent preference for children.

\section{CONCLUSION}

The expansion of the old-age pension program in South Africa led to an improvement in the health and nutrition of girls, reflected in the weight for height of all girls and the height for age of the youngest girls. It had no discernible effect on boys. The effect is entirely due to pensions received by women.

Pensions received by women improved the height-for-age $z$-scores of younger girls by at least 1.16 standard deviations, and the weight-for-height $z$-scores of

20. In an earlier version of this article I argue that to convincingly reject the unitary model of the household, one needs exogenous permanent shocks to the nonlabor income of both household members, occurring after marriage, which is exactly what the pension program provides (Duflo 2000b). 
girls by 1.19 standard deviations. South African girls are on average 1.20 standard deviations smaller than U.S. children, so the estimates suggest that pensions received by women helped girls bridge the entire gap in stature with U.S. children.

The pension represented a large income transfer, so a finding of large effects on child nutritional status perhaps appears unsurprising. Still, the fact that pensions received by women led to a sizable increase in the height of girls shows that cash transfers can have an important effect on child nutritional status. There is almost no evidence of this kind for developing economies, ${ }^{21}$ but the available evidence for the United States suggests that cash transfers do not have substantial effects on child welfare (Mayer 1997; Currie 1995).22 One would expect these effects to be larger in developing economies, where households are more likely to face credit constraints; this article confirms that intuition.

Of course, the article's findings cannot be easily generalized to other developing economies. The old-age pension program was on such a large scale that it could not be replicated outside the particular context of the postapartheid era in South Africa. Moreover, there could be nonlinearity in the effect of a cash transfer, making it difficult to infer what the effect would have been had it been implemented on a different scale.

Thus, the most important finding may be that this large cash transfer had no effect if it was received by a man. This suggests that the efficiency of transfer programs may vary depending on how they are administered. In South Africa the program is naturally biased toward women, both because women can claim the pension earlier (at age 60, compared with age 65 for men) and because women tend to live longer. Without this feature the program would have a smaller effect on the nutrition of young children.

The distinction between men and women does not accord with the South African constitution, and there is some pressure to remove it. But the effectiveness of the pension program as a tool for transferring resources to young children would argue for increasing the bias toward women. Even so, pensions received by men could affect other dimensions of investment in children's human capital not measured here (such as education), so this implication needs to be carefully assessed. Future work should investigate whether the difference between women and menand between girls and boys-is also found for other outcomes. Moreover, it is important to understand the reason for the larger effect on girls. Is it because they were lagging further behind ${ }^{23}$ Is the effect specific to income received by grandmothers? If so, why do grandmothers prefer girls?

21. An exception is a study by Carvalho (2000) showing that an expansion of the old-age pension program in Brazil led to an increase in educational attainment among girls and to a decrease in child labor among boys.

22. Shea (1997) studies whether outcomes for children (education and subsequent labor earnings) in the United States are correlated with their father's union status, job loss, or industry of employment and finds no effect except among the poorest families.

23. The available evidence does not allow an answer to this question. $z$-Scores cannot be easily interpreted, because the reference population consists of well-nourished U.S. children. Nor can they be compared across genders, because the standardization may distort the data in different ways for boys and girls. 


\section{ApPENDiX}

Table A-I. Effect of Pension Eligibility on Pension Receipt: First-Stage Regressions

\begin{tabular}{|c|c|c|c|c|}
\hline & $\begin{array}{c}\text { Woman } \\
\text { receives } \\
\text { pension } \\
\text { (1) }\end{array}$ & $\begin{array}{c}\text { Man } \\
\text { receives } \\
\text { pension } \\
(2)\end{array}$ & $\begin{array}{c}\text { Woman } \\
\text { receives } \\
\text { pension } \\
\times \text { YOUNG } \\
\quad(3)\end{array}$ & $\begin{array}{c}\text { Man } \\
\text { receives } \\
\text { pension } \\
\times \text { YOUNG } \\
\quad(4)\end{array}$ \\
\hline \multicolumn{5}{|l|}{ Girls } \\
\hline Woman eligible & $\begin{array}{l}0.51 * \\
(0.057)\end{array}$ & $\begin{array}{r}0.025 \\
(0.03)\end{array}$ & & \\
\hline Man eligible & $\begin{array}{c}0.077 \\
(0.052)\end{array}$ & $\begin{array}{l}0.41 * \\
(0.064)\end{array}$ & & \\
\hline Woman eligible $\times$ YOUNG & & & $\begin{array}{l}0.62 * \\
(0.062)\end{array}$ & $\begin{array}{c}0.017 \\
(0.042)\end{array}$ \\
\hline Man eligible $\times$ YOUNG & & & $\begin{array}{c}0.12 \\
(0.10)\end{array}$ & $\begin{array}{c}0.60 * \\
(0.094)\end{array}$ \\
\hline Observations & 1533 & 1533 & 1533 & 1533 \\
\hline \multicolumn{5}{|l|}{ Boys } \\
\hline Woman eligible & $\begin{array}{l}0.55^{*} \\
(0.052)\end{array}$ & $\begin{array}{c}0.021 \\
(0.036)\end{array}$ & & \\
\hline Man eligible & $\begin{array}{c}0.028 \\
(0.054)\end{array}$ & $\begin{array}{l}0.39 * \\
(0.067)\end{array}$ & & \\
\hline Woman eligible $\times$ YOUNG & & & $\begin{array}{l}0.70 * \\
(0.050)\end{array}$ & $\begin{array}{c}0.025 \\
(0.045)\end{array}$ \\
\hline Man eligible $\times$ YOUNG & & & $\begin{array}{l}-0.071 \\
(0.059)\end{array}$ & $\begin{array}{c}0.59 * \\
(0.069)\end{array}$ \\
\hline Observations & 1627 & 1627 & 1627 & 1627 \\
\hline \multicolumn{5}{|l|}{ Control variables } \\
\hline Presence of older members ${ }^{a}$ & Yes & Yes & No & No \\
\hline Family background variables ${ }^{b}$ & Yes & Yes & Yes & Yes \\
\hline $\begin{array}{l}\text { Family background variables } \times \\
\text { age dummy variables }\end{array}$ & Yes & Yes & Yes & Yes \\
\hline Age dummy variables ${ }^{c}$ & Yes & Yes & Yes & Yes \\
\hline
\end{tabular}

*Significant at the 5 percent level

Note: Standard errors (robust to correlation of residuals within households and heteroscedasticity) are in parentheses.

aDummy variables for whether there is a woman over age 50 , a man over age 50 , a woman over age 56 , a man over age 56, a man over age 61.

'Father's age and education; mother's age and education; or metropolitan residence; size of household; and number of members ages 0-5, 6-14, 15-24, 25-49, and over 50.

'Dummy variables for whether the child was born in 1991, 1990, or 1989.

Source: Author's calculations.

\section{REFERENCES}

Ashworth, Ann. 1969. "Growth Rates in Children Recovering from Protein-Calorie Malnutrition." British Journal of Nutrition 23:835-45.

Balazs, R., T. Jordan, P. D. Lewis, and A. J. Patel. 1986. "Undernutrition and Brain 
Development.” In F. Falkner and J. M. Tanner, eds., Human Growth: A Comprehensive Treatise, vol. 3, 2d ed. New York: Plenum.

Barker, D. J. P. 1990. “The Fetal and Infant Origins of Adult Disease.” British Medical Journal 301(6761):1111.

Bertrand, Marianne, Douglas Miller, and Sendhil Mullainathan. 1999. "Public Policy and Extended Families: Evidence from South Africa." Massachusetts Institute of Technology, Department of Economics, Cambridge, Mass.; and Princeton University, Department of Economics, Princeton, N.J.

Browning, Martin, and Pierre-André Chiappori. 1998. "Efficient Intrahousehold Allocations: A General Characterization and Empirical Tests." Econometrica 66(6):1241-78.

Budlender, Debbie. 2000. "Human Development." In Julian May, ed., Poverty and Inequality in South Africa: Meeting the Challenge. Johannesburg: Zed.

Carvalho, Irineu. 2000. "Household Income as a Determinant of Child Labor and School Enrollment in Brazil: Evidence from a Social Security Reform.” Massachusetts Institute of Technology, Department of Economics, Cambridge, Mass.

Case, Anne, and Angus Deaton. 1998. "Large Cash Transfers to the Elderly in South Africa." Economic Journal 108(450):1330-61.

Chiappori, Pierre-André. 1988. "Rational Household Labor Supply.” Econometrica 56(1):63-90.

- 1992. "Collective Labor Supply and Welfare." Journal of Political Economy 100(3):437-67.

Currie, Janet. 1995. Welfare and the Well-Being of Children; Fundamentals of Pure and Applied Economics 59. Chur, Switzerland: Harwood Academic.

Dasgupta, Partha. 1993. Inquiry into Well-Being and Destitution. Oxford: Clarendon.

Duflo, Esther. 2000a. "Child Health and Household Resources in South Africa: Evidence from the Old Age Pension Program." American Economic Review 90(2):393-98.

- 2000b. "Grandmothers and Granddaughters: Old Age Pension and Intra-Household Allocation in South Africa.” NBER Working Paper 8061. National Bureau of Economic Research, Cambridge, Mass.

Edmonds, Eric, Kristin Mammen, and Douglas Miller. 2001. "Rearranging the Family? Household Composition Responses to Large Pension Receipts.” Dartmouth College, Department of Economics, Hanover, N.H.

Gertler, Paul, and Simone Boyce. 2001. “An Experiment in Incentive-Based Welfare: The Impact of Progresa on Health in Mexico.” Haas School of Business, University of California at Berkeley.

Jensen, Robert. 1998. "Three Essays on Microeconomics and Social Policy in South Africa.” Ph.D. diss., Princeton University, Department of Economics. Princeton, N.J.

Le Roux, Pieter. 1995. "Poverty, Social Policies and the Reconstruction and Development Programme.” Working Paper. Institute for Theological and Interdisciplinary Research, Cape Town, South Africa.

Lund, Frances. 1993. "State Social Benefits in South Africa." International Social Security Review 46(1):5-25.

Lundberg, Shelly J., Robert A. Pollak, and Terence J. Wales. 1996. "Do Husbands and Wives Pool Their Resources? Evidence from the United Kingdom Child Benefit.” Journal of Human Resources 32(4):463-80. 
Martorell, R., and J. P. Habicht. 1986. "Growth in Early Childhood in Developing Countries.” In F. Falkner and J. M. Tanner, eds., Human Growth: A Comprehensive Treatise, vol. 3, 2d ed. New York: Plenum.

Mayer, Susan E. 1997. What Money Can't Buy: Family Income and Children's Life Chances. Cambridge, Mass.: Harvard University Press.

Miguel, Edward, and Michael Kremer. 2001. "Worms: Education and Health Externalities in Kenya." NBER Working Paper 8481. National Bureau of Economic Research, Cambridge, Mass.

Schultz, T. Paul. 1999. "Productive Benefits of Improving Health: Evidence from LowIncome Countries." Yale University, Department of Economics, New Haven, Conn.

— . 2000. "Final Report: The Impact of Progresa on School Enrollments." Yale University, Department of Economics, New Haven, CT; and International Food Policy Research Institute, Washington, D.C.

Scrimshaw, Nevin S. 1997. "The Relation between Fetal Malnutrition and Chronic Disease in Later Life." British Medical Journal 315:825-26.

Shea, John. 1997. “Does Parents' Money Matter?” NBer Working Paper 6026. National Bureau of Economic Research, Cambridge, Mass.

Strauss, John, and Duncan Thomas. 1998. "Health, Nutrition, and Economic Development." Journal of Economic Literature 36(2):766-817.

Thomas, Duncan. 1990. "Intrahousehold Resource Allocation: An Inferential Approach.” Journal of Human Resources 25(4):635-64.

. 1994. "Like Father, Like Son, Like Mother, Like Daughter: Parental Education and Child Health." Journal of Human Resources 29:950-88.

Van der Berg, Servaas. 1994. "Issues in South African Social Security." Office memorandum. World Bank, Washington, D.C.

wно (World Health Organization) Working Group. 1986. "Use and Interpretation of Anthropometric Indicators of Nutritional Status." Bulletin of the World Health Organization 64(6):929-41. 